\title{
openheart Prognostic significance of BMI after PCI treatment in ST-elevation myocardial infarction: a cohort study from the Swedish Coronary Angiography and Angioplasty Registry
}

\author{
Shabbar Jamaly (D) ,1,2 Bjorn Redfors, ${ }^{1,2}$ Elmir Omerovic, ${ }^{1,2}$ Lena Carlsson, ${ }^{2}$ \\ Kristjan Karason ${ }^{1,2,3}$
}

To cite: Jamaly S, Redfors B, Omerovic E, et al. Prognostic significance of BMl after PCl treatment in ST-elevation myocardial infarction: a cohort study from the Swedish Coronary Angiography and Angioplasty Registry. Open Heart 2021;8:e001479. doi:10.1136/ openhrt-2020-001479

Received 17 October 2020 Revised 12 January 2021 Accepted 25 January 2021

Check for updates

\section{(c) Author(s) (or their} employer(s)) 2021. Re-use permitted under CC BY. Published by BMJ.

${ }^{1}$ Department of Cardiology, Sahlgrenska University Hospital, Gothenburg, Sweden

${ }^{2}$ Department of Molecular and Clinical Medicine, Institute of Medicine, Sahlgrenska Academy at University of Gothenburg, Gothenburg, Sweden

${ }^{3}$ Transplant Institute, Sahlgrenska University Hospital, Gothenburg, Sweden

\section{Correspondence to}

Dr Shabbar Jamaly; shabbar. jamaly@gu.se

\section{ABSTRACT}

Background Obesity along with clustering of cardiovascular risk factors is a promoter for coronary artery disease. On the other hand, a high body mass index (BMI) appears to exert a protective effect with respect to outcomes after a coronary artery event, termed the obesity paradox.

Methods The Swedish Coronary Angiography and Angioplasty Registry collects information on all patients who undergo percutaneous coronary intervention (PCl) for ST-elevation myocardial infarction (STEMI) in Sweden along with demographic and procedure-related data. We studied the predictability of four categories of BMI for 1year all-cause mortality in people with STEMI undergoing PCl.

Results Among 25384 patients, mean (SD) age 67.7 (12.1) years and $70.2 \%$ male, who underwent PCl for STEMI, a total of $5529(21.8 \%)$ died within 1 year. Using normal weight (BMl $\left.18.5-24.9 \mathrm{~kg} / \mathrm{m}^{2}\right)$ as a reference, subjects with obesity $\left(\mathrm{BMI} \geq 30 \mathrm{~kg} / \mathrm{m}^{2}\right)$ had a low 1-year all-cause mortality risk in unadjusted analysis, HR 0.59 ( $95 \% \mathrm{Cl} 0.53$ to 0.67 ). However, after adjustment for age, sex and other covariates, the difference became nonsignificant, HR 0.88 (95\% Cl 0.75 to 1.02). Patients with overweight (BMI $25.0-29.9 \mathrm{~kg} / \mathrm{m}^{2}$ ) had the lowest 1-year mortality risk in analysis adjusted for age, sex and other covariates, HR 0.87 (95\% Cl 0.79 to 0.97 ), whereas those with underweight $\left(\mathrm{BMI}<18.5 \mathrm{~kg} / \mathrm{m}^{2}\right)$ had the highest mortality in both unadjusted HR $2.22(95 \% \mathrm{Cl} 1.69$ to 2.92) and adjusted analysis, HR $1.62(95 \% \mathrm{Cl} 1.18$ to 2.23$)$. Conclusion The protective effect of obesity with respect to 1-year mortality after coronary intervention became non-significant after adjusting for age, sex and relevant covariates. Instead, overweight people displayed the lowest risk and underweight individuals the highest risk for adjusted all-cause mortality.

Trial registration number NCT02311231.

\section{INTRODUCTION}

Obesity, together with associated clustering of cardiovascular risk factors, such as hypertension $^{1}$ dyslipidaemia ${ }^{2}$ and diabetes, ${ }^{3}$ is a

\section{Key questions}

What is already known about this subject?

- Obesity along with clustering of cardiovascular risk factors is a promoter for coronary artery disease. On the other hand, a high body mass index (BMI) $\left(>30 \mathrm{~kg} / \mathrm{m}^{2}\right)$ appears to exert a protective effect with respect to outcomes after a coronary artery event termed the obesity paradox.

What does this study add?

- In unadjusted analysis, subjects with a BMI higher than $30 \mathrm{~kg} / \mathrm{m}^{2}$ had the lowest 1 -year all-cause mortality after percutaneous coronary intervention (PCI) for ST-elevation myocardial infarction when compared with people with lower BMI categories. However, after adjusting for age, sex and covariates, the protective effect of obesity became nonsignificant. Instead, people with overweight (BMI $25-29.9 \mathrm{~kg} / \mathrm{m}^{2}$ ) showed the lowest risk for 1-year all-cause mortality.

How might this impact on clinical practice?

- We conclude that the apparent protective effect of obesity post-PCl could be due to confounders and speculate that a greater muscle mass together with enhanced cardiorespiratory fitness are more important with respect to outcomes after a coronary event.

strong promoter for cardiovascular disease morbidity and mortality. ${ }^{4-6}$ Weight control is considered to be of fundamental importance in primary prevention aimed at reducing the overall incidence of cardiovascular disease ${ }^{7}$ and is also targeted in secondary preventive programmes intended to improve outcome in patients with established cardiovascular disease. $^{89}$

Still, a certain hesitancy has arisen concerning the beneficial effects of weight loss as a secondary prevention practice since several epidemiological studies have 
suggested that obesity may be protective in patients with coronary artery disease undergoing intervention. ${ }^{10-12}$ The apparent favourable effect of obesity on outcomes after coronary interventions, known as the 'obesity paradox', has generated a substantial amount of controversy. ${ }^{13} \mathrm{~A}$ protective effect of excess body fat is somewhat counterintuitive and a mechanism involving reverse causality has been suggested. ${ }^{14}$ Also, body fat distribution, cardiorespiratory fitness and unintentional weight loss could constitute confounders accounting for the somewhat paradoxical relationship between obesity and prognosis after coronary intervention. ${ }^{15}$

The aim of the present study was to evaluate the relationship between body fatness, divided up as four different body mass index (BMI) categories, and mortality in a large Swedish population undergoing percutaneous coronary intervention (PCI) due to an ST-elevation myocardial infarction (STEMI).

\section{PATIENTS AND METHODS \\ Patient population}

The Swedish Coronary Angiography and Angioplasty Registry (SCAAR) was established in 1992 and contains information about all coronary angiographies and PCIs (formerly known as angioplasty with stent) ${ }^{10}$ Each catheterisation procedure is described with approximately 50 angiography and 200 PCI variables, including both demographic and procedure-related data. The registry is financed by the Swedish government and the Association of Local Authorities and Regions and is supported by the Swedish Heart Association, the National board of Health and Welfare and the Swedish Heart and Lung Foundation

All consecutive patients undergoing PCI for STEMI in Sweden between 1 January 2011 and 31 May 2018 were included in the study. STEMI was defined according to the European Society of Cardiology criteria ${ }^{16}$ as a condition when there is evidence of myocardial injury defined as a dynamic change in cardiac troponin values with at least one value above the 99th percentile upper reference limit, or a persistent chest discomfort suggestive of myocardial ischaemia, along with an ST-segment elevation in at least two contiguous leads. Body weight and height, either measured or self-reported, were entered in the register at the time of the intervention. BMI, as a measure of nutritional status, was calculated as the weight in kilograms divided by the square of the height in metres. Other patient characteristics and information on comorbidities were imported into the register from medical records. All patients admitted to the cardiac care unit are informed both verbally and in writing about their participation in the registry. The investigation conformed with the principles outlined in the Declaration of Helsinki.

\section{Outcome measures}

The primary endpoints were mortality rates at 30 days and at 1 year. All Swedish citizens have a specific personal identity number that is recorded in connection with all healthcare contacts and makes it feasible to follow how the Swedish population interacts with the healthcare system. The SCAAR registry obtains data on patients' vital status from the Swedish Cause of Death Register, which originates from 1952 and includes the cause of mortality for all of citizens registered in Sweden at the time of their death. ${ }^{17}$

\section{Statistics}

Statistical analyses were performed with SAS V.9.4 statistical software packages (SAS Institute, Cary, NC). Study participants were divided into four categories according to their nutritional status as recommended by $\mathrm{WHO}^{18}$ : underweight (BMI $<18.5 \mathrm{~kg} / \mathrm{m}^{2}$ ), normal weight (BMI $18.5-24.9 \mathrm{~kg} / \mathrm{m}^{2}$ ), overweight (BMI $25.0-29.9 \mathrm{~kg} / \mathrm{m}^{2}$ ) and obese $\left(\right.$ BMI $\left.\geq 30.0 \mathrm{~kg} / \mathrm{m}^{2}\right)$. Data are presented for the total study population and for each BMI group separately as means and SDs, medians and IQRs, or numbers and percentages. Comparisons between groups at baseline based on a complete case analysis were performed with ANOVA for normally distributed numerical data, $\chi^{2}$ test for categorical data and Kruskal-Wallis rank-sum test for non-normally distributed data. The number of complete cases with data for each variable is given as the denominators in table 1 .

For the first primary endpoint, participants were followed until death or for 30 days; and for the secondary primary end point, participants were followed until death or up to 1 year. At these time points, the SCAAR and Cause of Death Register were linked. Death is presented as a cumulative incidence function and comparison between groups was performed with the log-rank test. Persons who emigrated or were alive at the end of the 1-month or 12-month follow-up, respectively, were treated as censored observations. Death within the first 30 days was included as an event in the analysis for outcome at 1-year follow-up since we felt that that the risk for bias was low and, therefore, a landmark analysis redundant. Furthermore, since there were no competing events, it was not necessary to take this into account in the statistical analysis.

To evaluate the association between BMI categories and mortality, univariable and multivariable-adjusted HRs were calculated using Cox proportional-hazards regression models. We performed a primary investigation employing a complete case analysis. Thereafter, to handle missing data, we performed a secondary examination after multiple imputation missing pattern (MIMP) with the missing at random (MAR) assumption. The first model was unadjusted, the second model was adjusted for age, the third model was adjusted for age and sex, and the fourth and final model was adjusted for all covariates listed in table 1 . The reference group was defined as the normal nutritional category as defined by WHO corresponding to a BMI of $18.5-24.9 \mathrm{~kg} / \mathrm{m}^{2}$. All models were specified prior to conducting analyses and adjusted for preselected baseline risk factors considered of importance for the outcome. Further, the causal directed 


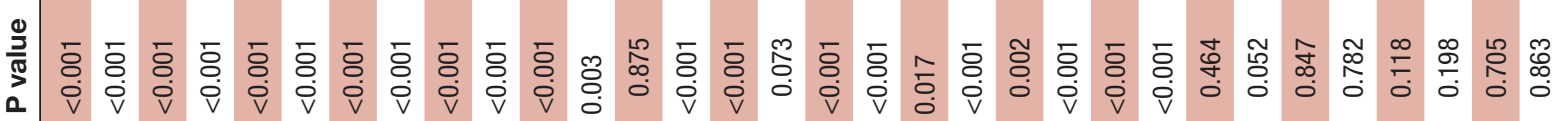

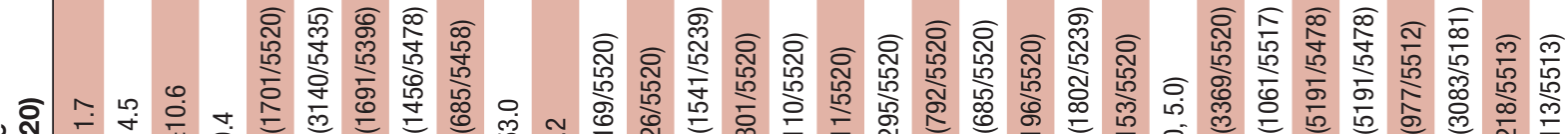

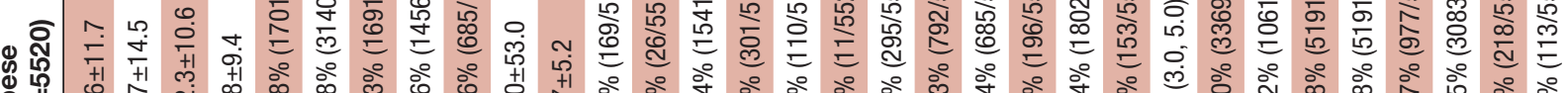
o II 0 성 。

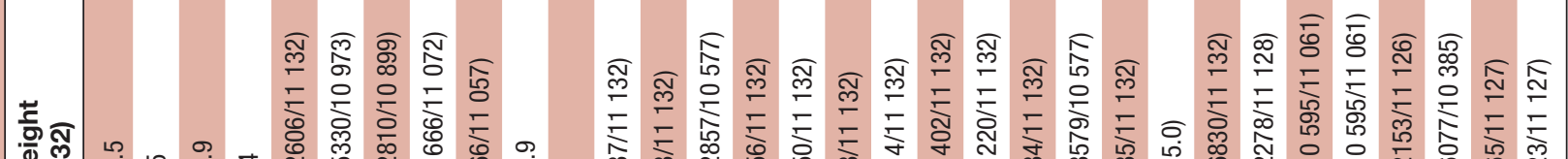

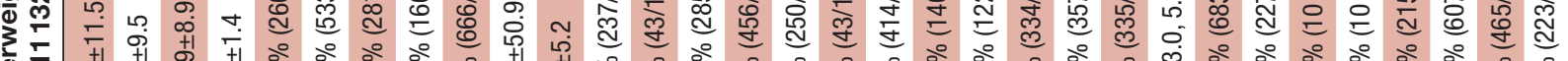

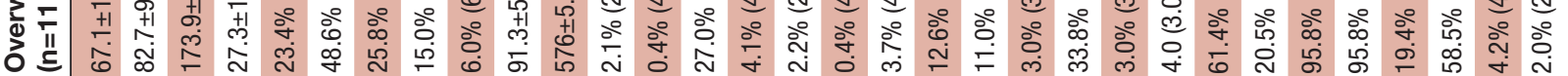

출

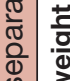

舟

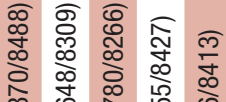

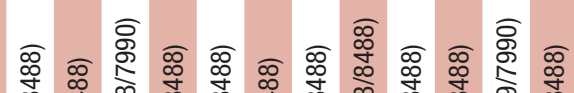

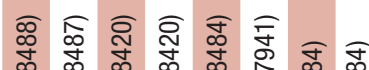

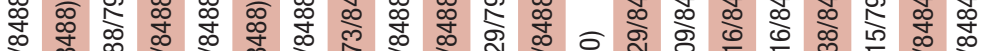

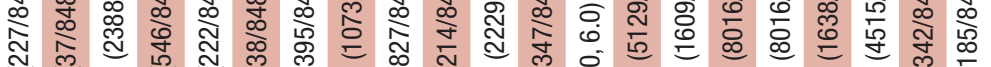

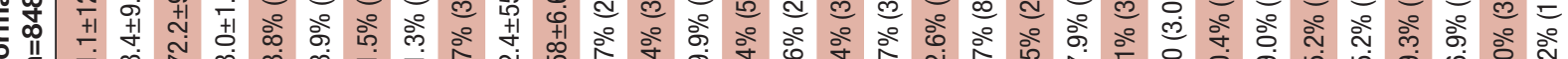

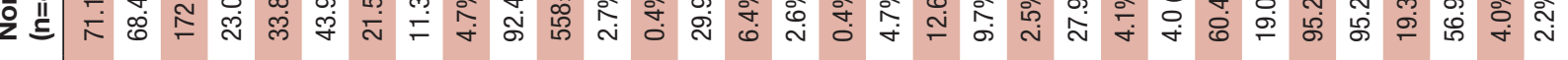

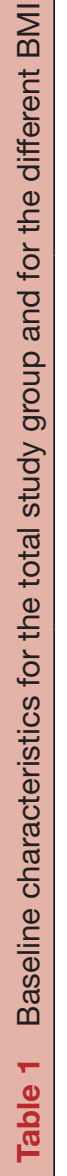

竞

舟手

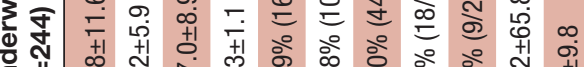

.
ป 光 
acyclic graph approach was applied when adjusting for confounding. An adjusted mortality analysis for the first 30 days was also considered, but due to few events, we concluded that the study was underpowered for this. Penalised spline regression was applied to study relationship between BMI as a continuous variable and all-cause mortality. The likelihood ratio test was used to examine the consistency of the association between BMI categories and mortality in the following subgroups defined by baseline characteristics: males versus females; age $>65$ years versus age $\leq 65$ years; presence or absence of diabetes; smokers versus non-smokers. All statistical tests were twotailed and $p$ values of $<0.05$ were considered statistically significant.

\section{RESULTS}

\section{Patient characteristics}

Between 1 January 2011 and 31 May 2018, a total of 25384 patients underwent coronary artery catheterisation for STEMI at 29 PCI centres in Sweden. Among these, a total of $1304(5.1 \%)$ died within 30 days of PCI and $5529(21.8 \%)$ died within 1 year after the intervention. Baseline characteristics for the total study group, and for different BMI categories separately, are presented in table 1 . People with obesity tended to be younger and have a more adverse cardiovascular risk factor profile with higher frequencies of hypertension, hyperlipidaemia and diabetes as compared with those in other BMI categories, but were less often smokers than those who were underweight. Underweight patients were more often females, smoked more frequently and had a higher prevalence of chronic obstructive pulmonary disease (COPD). The angiographic burden of coronary artery disease and number of days hospitalised were similar among patients with different BMI categories.

\section{Unadjusted 30-day and 1-year mortality in different BMI classes}

Unadjusted 30-day all-cause mortality for different BMI categories are presented with cumulative incidence curves in figure 1. Patients who were underweight had the highest 30 -day mortality $(13.3 \%)$, followed by patients with normal weight $(6.6 \%)$. Overweight and obese patients had somewhat lower cumulative mortality $(4.3 \%$ and $4.2 \%$, respectively). The overall log-rank $\mathrm{p}$ value was $<0.001$.

Unadjusted 1-year all-cause mortality for different BMI categories is presented with cumulative incidence curves in figure 2. Again, there was a substantial difference in mortality between different BMI classes with the highest risk in the underweight group (23.3\%) followed by those with normal weight $(11.3 \%)$. Patients who were overweight or obese had a lower 1-year mortality risk $(7.3 \%$ and $6.9 \%$, respectively). The overall log-rank $\mathrm{p}$ value was $<0.001$.

\section{Adjusted 1-year mortality in different BMI categories}

Figure 3 presents a Forest plot of HRs displayed in log-10 scale for 1-year all-cause mortality in different BMI categories using the normal weight population as a reference group. People with underweight had the highest mortality compared with people of normal weight in both unadjusted and multi-adjusted analysis. In contrast, patients with overweight had a lower mortality risk compared with normal weight in both unadjusted and
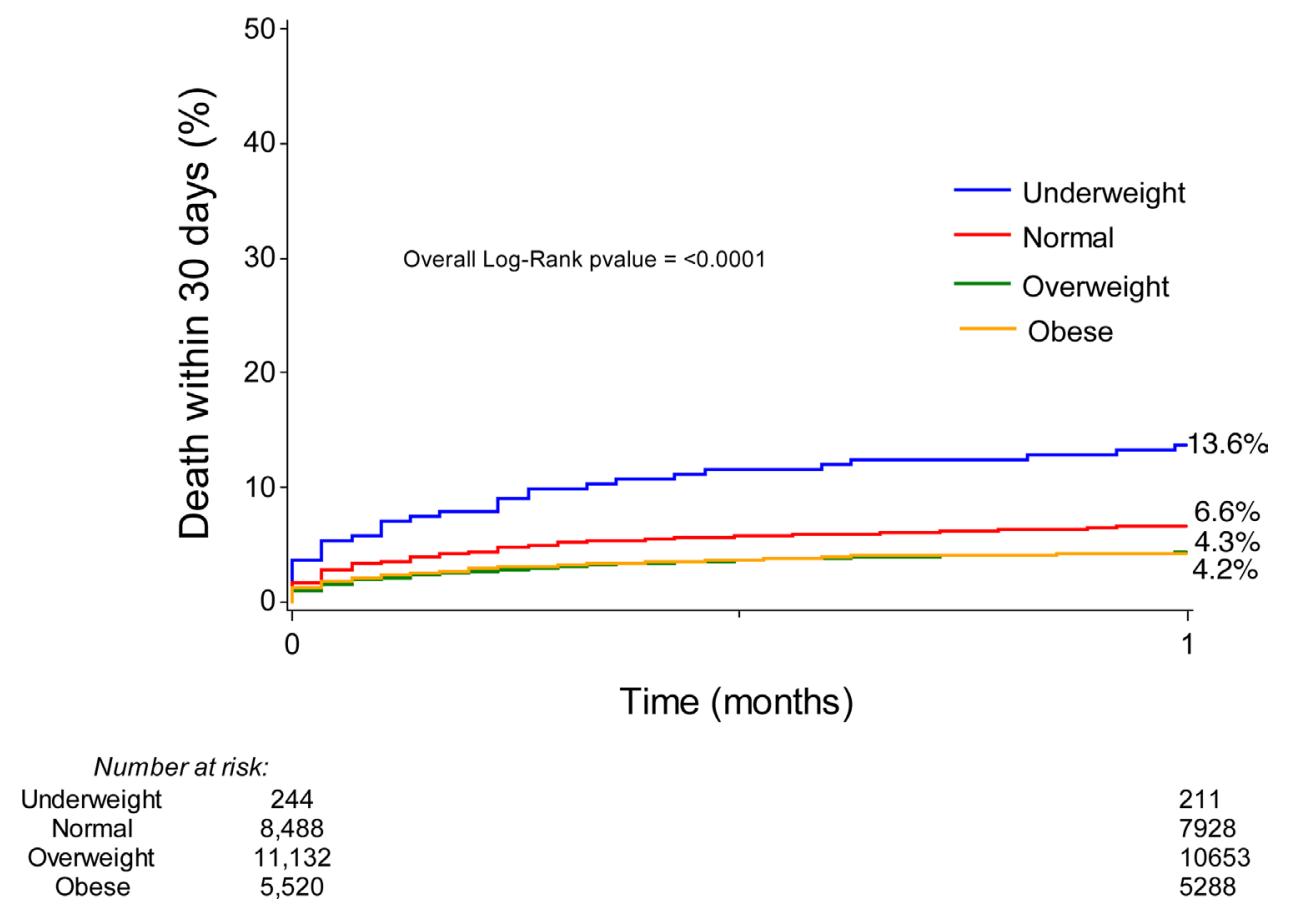

Figure 1 Thirty-day all-cause mortality after percutaneous coronary intervention in STEMI for different body mass index categories. 


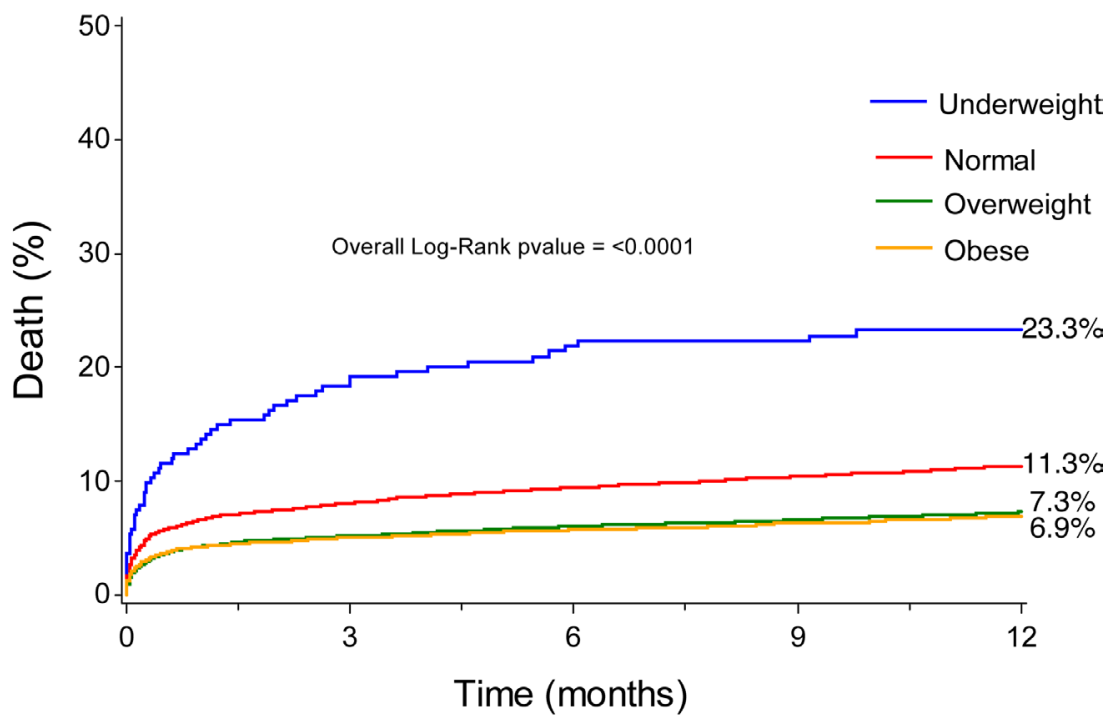

\begin{tabular}{cc}
\multicolumn{2}{c}{ Number at risk: } \\
Underweight & 244 \\
Normal & 8,488 \\
Overweight & 11,132 \\
Obese & 5,520
\end{tabular}

187
7,543
10,189
5,022

172
7,150
9,756
4,793

164
6,821
9,281
4,574

158

6,512

8,863

Figure 2 One-year all-cause mortality after percutaneous coronary intervention in STEMI for different body mass index categories.

multi-adjusted analyses. Patients with obesity had a lower risk for death than normal weight subjects in unadjusted analysis, but this difference became non-significant in the multi-adjusted analysis considering age, sex and other covariates. Still the HR did not differ much from the overweight group and it is possible that the lack of significance is a type II statistical error.

In figure 4, we examined the association between BMI as a continuous variable and unadjusted and adjusted all-cause mortality using fractional polynomial Cox

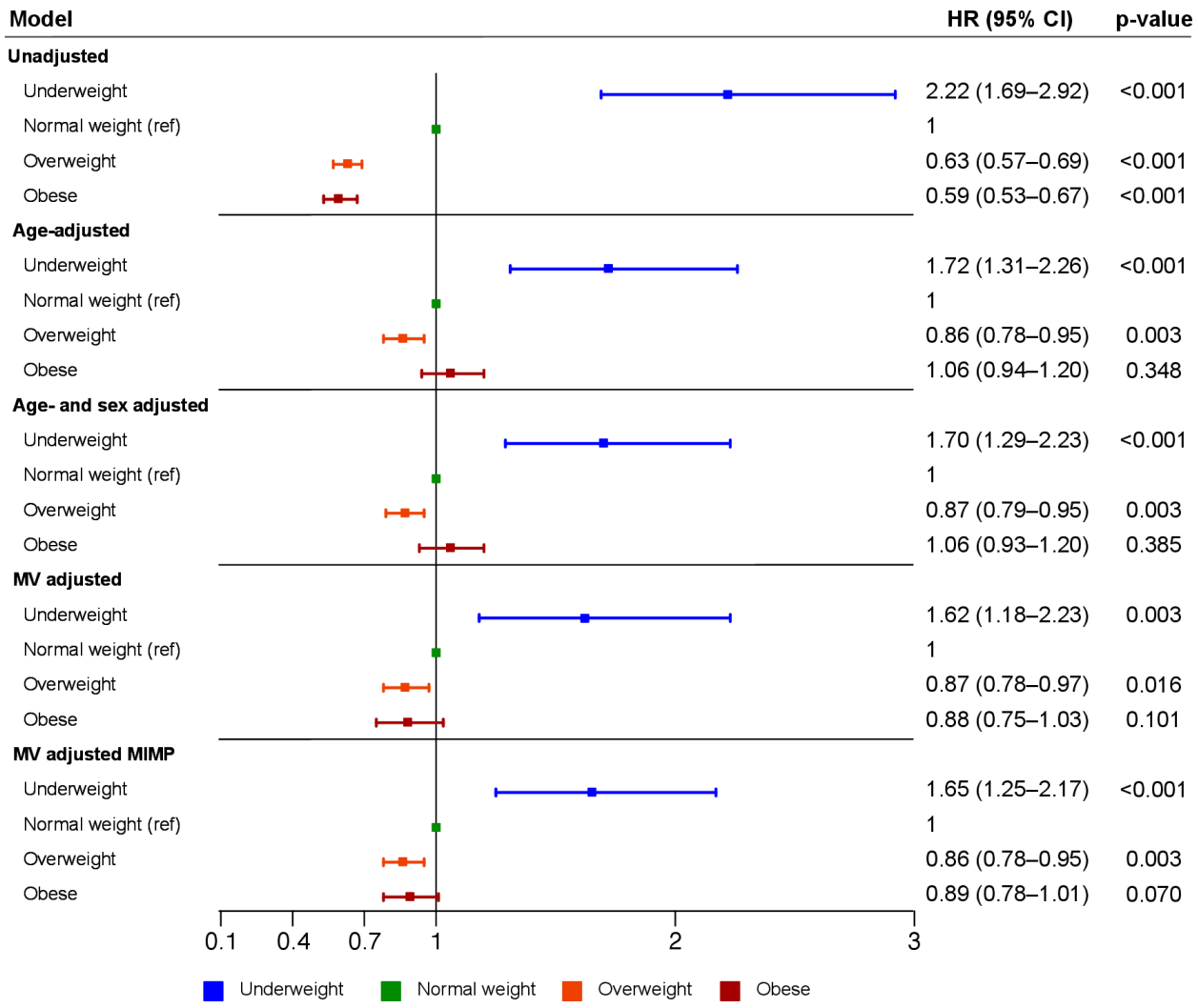

Figure 3 Unadjusted and adjusted risk for mortality $(95 \% \mathrm{Cl})$ in patients with STEMI using log-10 scale for the $\mathrm{x}$-axis. 

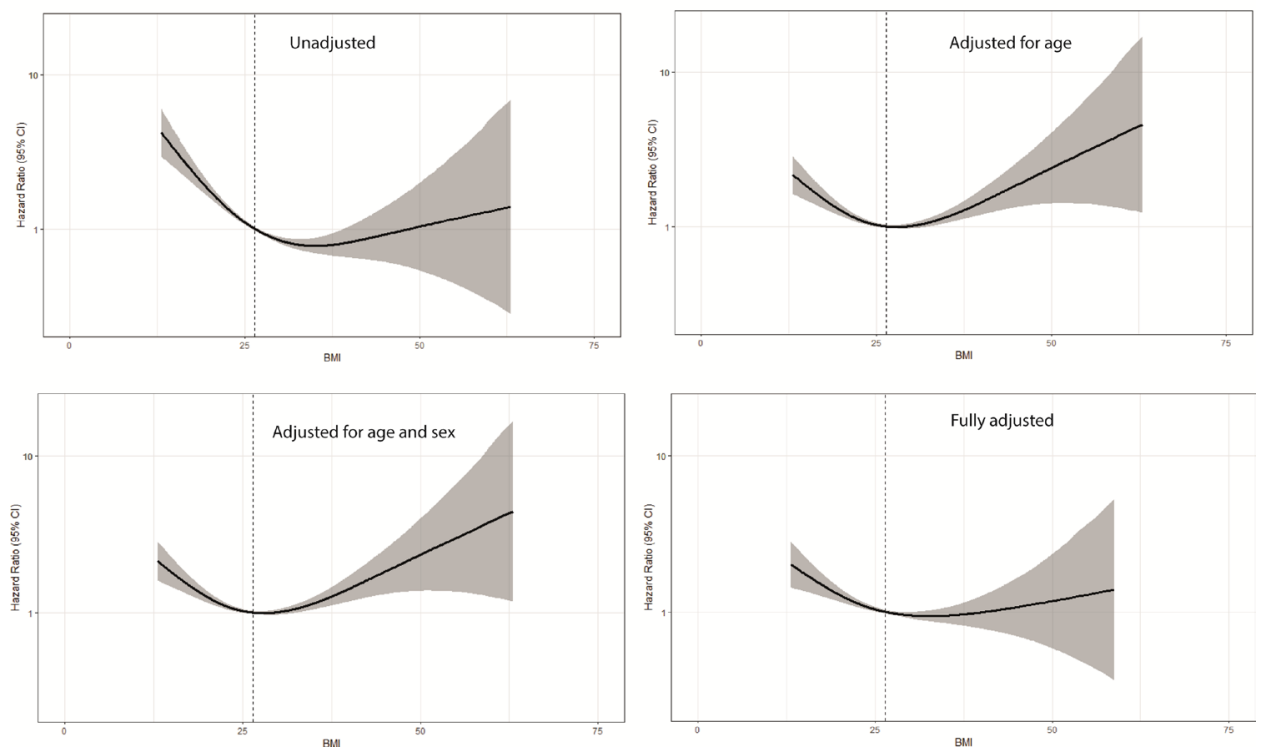

Figure 4 Unadjusted and adjusted fractional polynomial Cox proportional-hazards regression $(95 \% \mathrm{Cl}$, shaded area) with continuous risk relationship between body mass index and all-cause mortality after percutaneous coronary intervention treatment for STEMI.

regression. In models adjusted for age and sex, the curves were U-shaped with a BMI/risk nadir between 25.0 and $29.9 \mathrm{~kg} / \mathrm{m}^{2}$. In the unadjusted and fully adjusted model, the right side of the curve flattened with wide CIs. In an interaction analysis, the relationship between BMI categories and risk of death was similar in subgroups of selected baseline characteristics (table 2).

\section{DISCUSSION}

In the present study, unadjusted statistical analysis showed that people with obesity $\left(\mathrm{BMI} \geq 30.0 \mathrm{~kg} / \mathrm{m}^{2}\right)$ had the lowest 30-day and 1-year all-cause mortality after coronary intervention due to STEMI, when compared with the subjects of normal weight (BMI $18.5-24.9 \mathrm{~kg}$ / $\mathrm{m}^{2}$ ). Thus, in these analyses, our results were in line with the obesity paradox. However, after adjustment for age and sex, the effect of obesity on mortality did not differ from that observed in people of normal weight. Instead, when age and sex had been considered, people with overweight (BMI $25-29.9 \mathrm{~kg} / \mathrm{m}^{2}$ ) had the lowest mortality. In the 1-year model adjusted for all covariates, people with overweight still had the lowest death rate, whereas the risk in people with obesity did not differ from that of those with normal weight. However, increasing BMI as a continuous variable in the fully adjusted 1-year analysis, the risk curve flattened out with a wide CI, making it difficult to interpret. Of notice, people with obesity do have a lower mortality in unadjusted analysis and did not display a higher mortality than those of normal weight in the fully adjusted model. On the other hand, people who were underweight $\left(B M I<18.5 \mathrm{~kg} / \mathrm{m}^{2}\right)$ had a mortality that was substantially higher than that observed for other BMI classes.
Previous publications, including a report from the Framingham heart study, ${ }^{19}$ results from the Canadian APPROACH register ${ }^{20}$ and data from the SCAAR register ${ }^{12}$ showed that in patients with established coronary artery disease, the lowest adjusted risk for mortality reached a nadir around a BMI of $35 \mathrm{~kg} / \mathrm{m}^{2}$. Furthermore, a metaanalysis by Wang $e t a l^{21}$ found lower all-cause mortality after myocardial infarction in a pooled group of overweight and obese subjects compared with people of normal weight. In contrast, Shahim and coworkers ${ }^{22}$ found no relationship between BMI and myocardial infarction size, or 1-year rates of death or heart failure hospitalisation, in a metaanalysis based on 2238 patients undergoing PCI.

The present study differed from the publications cited earlier regarding several aspects. Our patient population was considerably more homogenous compared with that in previous studies. The heterogenicity of previous study populations involved inclusion of patients undergoing PCI for STEMI, also subjects with NSTEMI treated with PCI or medication alone and in some cases management with coronary artery bypass grafting. Furthermore, in some of these studies, patients with underweight were excluded and adjustment for covariables was not performed as they were not available. It is not unlikely that these differences may explain the main disparity between previous reports and the present study, which showed that the lowest risk for 1-year all-cause mortality after adjusting for covariates was observed among overweight patients (BMI range $25.0-29.9 \mathrm{~kg} / \mathrm{m}^{2}$ ). Our findings are more in line with those of Flegal $e t a l^{23}$ who performed a meta-analysis including 2.9 million people and observed that the overweight group had a trend for better survival as compared with those who were obese. 


\begin{tabular}{|c|c|c|c|}
\hline Subgroups & $\begin{array}{l}\text { BMI } \\
\text { category }\end{array}$ & HR $(95 \%$ Cl) & $\begin{array}{l}\text { P-value for } \\
\text { interaction }\end{array}$ \\
\hline \multicolumn{4}{|l|}{ Sex } \\
\hline \multirow[t]{3}{*}{ Male } & Underweight & 2.074 (1.272 to 3.383$)$ & 0.68 \\
\hline & Overweight & 0.873 (0.756 to 1.008$)$ & \\
\hline & Obese & 0.890 (0.730 to 1.084$)$ & \\
\hline \multirow[t]{3}{*}{ Female } & Underweight & 1.394 (0.917 to 2.119) & \\
\hline & Overweight & 0.866 (0.721 to 1.039$)$ & \\
\hline & Obese & 0.864 (0.691 to 1.082$)$ & \\
\hline \multicolumn{4}{|l|}{ Age } \\
\hline \multirow[t]{3}{*}{$>65$} & Underweight & 1.595 (1.140 to 2.230$)$ & 0.38 \\
\hline & Overweight & 0.896 (0.794 to 1.011$)$ & \\
\hline & Obese & 0.911 (0.771 to 1.076$)$ & \\
\hline \multirow[t]{3}{*}{$\leq 65$} & Underweight & 1.964 (0.714 to 5.406$)$ & \\
\hline & Overweight & 0.687 (0.495 to 0.952$)$ & \\
\hline & Obese & 0.709 (0.492 to 1.023$)$ & \\
\hline \multicolumn{4}{|c|}{ Diabetes mellitus } \\
\hline \multirow[t]{3}{*}{ Diabetic } & Underweight & 2.591 (1.051 to 6.385$)$ & 0.62 \\
\hline & Overweight & 0.937 (0.736 to 1.194$)$ & \\
\hline & Obese & 0.877 (0.674 to 1.143$)$ & \\
\hline \multirow[t]{3}{*}{ Non-diabetic } & Underweight & 1.535 (1.092 to 2.157$)$ & \\
\hline & Overweight & 0.851 (0.748 to 0.968$)$ & \\
\hline & Obese & 0.898 (0.745 to 1.082$)$ & \\
\hline \multicolumn{4}{|l|}{ Smoking } \\
\hline \multirow{3}{*}{$\begin{array}{l}\text { Current } \\
\text { smoker }\end{array}$} & Underweight & 1.766 (1.017 to 3.066$)$ & 0.67 \\
\hline & Overweight & 0.782 (0.611 to 1.001$)$ & \\
\hline & Obese & 0.917 (0.674 to 1.249) & \\
\hline \multirow[t]{3}{*}{ Non-smoker } & Underweight & 1.550 (1.049 to 2.291$)$ & \\
\hline & Overweight & $0.893(0.786$ to 1.015$)$ & \\
\hline & Obese & 0.871 (0.733 to 1.034$)$ & \\
\hline
\end{tabular}

There were no significant interactions between dichotomous subgroups and BMI categories with respect to 1-year mortality. BMI, body mass index.

In the present study, underweight individuals (BMI $<18.5 \mathrm{~kg} / \mathrm{m}^{2}$ ) displayed the highest risk for all-cause 30 -day and 1-year mortality post-PCI in both unadjusted and adjusted statistical analyses. The separation between the mortality curves for the underweight group, as compared with other BMI categories, occurred early after PCI and showed, thereafter, a steeper upward slope during 1-year follow-up. We speculate that underweight patients may have an underlying pathophysiology that may generate a larger STEMI, more complications or impaired recoverability than subjects with a higher BMI. Also, previous epidemiological studies have observed a U-shaped relationship between BMI and all-cause mortality. ${ }^{24} 25$ This has mainly been attributed to smoking, ${ }^{26}$ respiratory illnesses ${ }^{27}$ and other underlying diseases. ${ }^{28}$ In the present study, underweight patients were more often smokers and had a higher prevalence of COPD. Thus, excessive mortality in underweight patients following PCI for STEMI could also be related to a higher occurrence of underlying comorbidities.

The relationship between categories of BMI and outcome was consistent across all subgroups studied for selected baseline characteristics. Hence, there was no difference between the two sexes, those with age below or above 65 years, those with or without diabetes mellitus, or those who smoked and those who did not.

In a review from 2017, Lavie $e t a l^{29}$ have listed several possible reasons or biases for the obesity paradox including younger patients, fewer smokers, better energy reserves, increased muscle mass and reverse causality due to frailty and cachexia in patients who are leaner, apart from other and unknown confounders. Of notice is that BMI as a measure of obesity does not differ between fat, muscle mass and skeletal weight. ${ }^{30}$ It is highly probable that an augmented muscle mass may act as a protective factor with respect to outcome after coronary interventions. ${ }^{31}$ Lavie et al studied patients with stable coronary artery disease and found that those with a higher lean body mass had better survival irrespective of their degree of fatness. ${ }^{32}$ Thus, the importance of muscle mass as an explanatory mechanism of the obesity paradox has probably been underestimated. Also, cardiorespiratory fitness is an important variable that may greatly influence the relationship between obesity and survival after PCI. ${ }^{33}$

\section{Strengths and limitations}

The strength of our study includes a large sample size of real-world data and a homogenous group of patients treated with PCI for STEMI. The main limitation is the observational nature of the study, which precludes us from making any causal inferences. As only surviving hospitalised patients are included, the possibility of selection bias, residual confounding and survival bias cannot be ruled out. BMI, as a measure of obesity, has its limitation as a measure of obesity since it does not distinguish between fat, muscle mass and skeletal weight. Neither waist circumference nor other measures of abdominal fatness were available in the SCAAR and, therefore, we were not able to take into account the distribution of body fat in our analyses. The role of unintentional weight loss was not controlled for and cause-specific mortality data were not studied. Data on death were collected by crosslinking the SCAAR with the Swedish Cause of Death Register, which is a high-quality virtually complete register of all deaths in Sweden since 1952, but is not adjudicated to establish cardiac versus non-cardiac causes of death.

\section{CONCLUSIONS}

Although people with obesity displayed lower mortality after treatment with PCI for STEMI as compared with a reference group with normal weight, the two groups showed similar outcomes after relevant covariates were considered. Assessed against the referent group, overweight patients showed the 
lowest 30-day and 1-year adjusted mortality risk, and underweight individuals the highest. We speculate that the amount of muscle mass and cardiorespiratory fitness may affect the relationship between BMI and outcome in patients with coronary artery disease.

\section{Twitter Shabbar Jamaly @shabby5253}

Contributors SJ: conceptualisation, investigation, methodology, project administration, visualisation, supervision, validation and writing original draft. Review and editing. Overall content guarantor. BR: conceptualisation, data curation, formal analysis and software. LC: writing —review and editing. E0: conceptualisation, data curation, writing — review and editing. KK: funding acquisition, writing — review and editing. Overall content guarantor.

Funding Research reported in this publication was funded by the Swedish federal government under the ALF agreement (ALFGBG-932636, ALFGBG-775351, ALFGBG633141).

Competing interests None declared.

Patient consent for publication Not required.

Ethics approval The study was approved by the Regional Ethical Board in Gothenburg.

Provenance and peer review Not commissioned; externally peer reviewed.

Data availability statement Data are available on reasonable request.

Open access This is an open access article distributed in accordance with the Creative Commons Attribution 4.0 Unported (CC BY 4.0) license, which permits others to copy, redistribute, remix, transform and build upon this work for any purpose, provided the original work is properly cited, a link to the licence is given, and indication of whether changes were made. See: https://creativecommons.org/ licenses/by/4.0/.

ORCID iD

Shabbar Jamaly http://orcid.org/0000-0002-5219-1297

\section{REFERENCES}

1 Hall JE, do Carmo JM, da Silva AA, et al. Obesity-induced hypertension: interaction of neurohumoral and renal mechanisms. Circ Res 2015;116:991-1006.

2 Vekic J, Zeljkovic A, Stefanovic A, et al. Obesity and dyslipidemia. Metabolism 2019;92:71-81.

3 Hossain P, Kawar B, El Nahas M. Obesity and diabetes in the developing world-a growing challenge. $N$ Engl J Med 2007;356:213-5.

4 Suwaidi JA, Wright RS, Grill JP, et al. Obesity is associated with premature occurrence of acute myocardial infarction. Clin Cardiol 2001;24:542-7.

5 Zhu J, Su X, Li G, et al. The incidence of acute myocardial infarction in relation to overweight and obesity: a meta-analysis. Arch Med Sci 2014;10:855-62.

6 Sjöström L, Peltonen M, Jacobson P, et al. Bariatric surgery and long-term cardiovascular events. JAMA 2012;307:56-65.

7 Graham I, Atar D, Borch-Johnsen K, et al. European guidelines on cardiovascular disease prevention in clinical practice: executive summary. Fourth Joint Task Force of the European Society of Cardiology and Other Societies on Cardiovascular Disease Prevention in Clinical Practice (constituted by representatives of nine societies and by invited experts). Eur J Cardiovasc Prev Rehabil 2007;14 Suppl 2:E1-40.

8 Piepoli MF, Hoes AW, Agewall S, et al. 2016 European guidelines on cardiovascular disease prevention in clinical practice: The Sixth Joint Task Force of the European Society of Cardiology and Other Societies on Cardiovascular Disease Prevention in Clinical Practice (constituted by representatives of 10 societies and by invited experts) Developed with the special contribution of the European Association for Cardiovascular Prevention \& Rehabilitation (EACPR). Eur Heart J 2016;37:2315-81.

9 Delling L, Karason K, Olbers T, et al. Feasibility of bariatric surgery as a strategy for secondary prevention in cardiovascular disease: a report from the Swedish obese subjects trial. J Obes 2010;2010:1-6.
10 Oreopoulos A, Padwal R, Norris CM, et al. Effect of obesity on shortand long-term mortality postcoronary revascularization: a metaanalysis. Obesity 2008;16:442-50.

11 Romero-Corral A, Montori VM, Somers VK, et al. Association of bodyweight with total mortality and with cardiovascular events in coronary artery disease: a systematic review of cohort studies. Lancet 2006;368:666-78.

12 Angerås $\mathrm{O}$, Albertsson $\mathrm{P}$, Karason $\mathrm{K}$, et al. Evidence for obesity paradox in patients with acute coronary syndromes: a report from the Swedish coronary angiography and angioplasty registry. Eur Heart J 2013;34:345-53.

13 Habbu A, Lakkis NM, Dokainish $\mathrm{H}$. The obesity paradox: fact or fiction? Am J Cardiol 2006;98:944-8.

14 Preston SH, Stokes A. Obesity paradox: conditioning on disease enhances biases in estimating the mortality risks of obesity. Epidemiology 2014;25:454-61.

15 Barry VW, Baruth M, Beets MW, et al. Fitness vs. fatness on all-cause mortality: a meta-analysis. Prog Cardiovasc Dis 2014;56:382-90.

16 Ibánez B, James S, Agewall S, et al. 2017 ESC guidelines for the management of acute myocardial infarction in patients presenting with ST-segment elevation. Rev Esp Cardiol 2017;70:1082.

17 Brooke HL, Talbäck M, Hörnblad J, et al. The Swedish cause of death register. Eur J Epidemiol 2017;32:765-73.

18 Anon. Obesity: preventing and managing the global epidemic. Report of a WHO consultation. World Health Organ Tech Rep Ser 2000;894:i-xii. 1-253.

19 Oreopoulos A, McAlister FA, Kalantar-Zadeh K, et al. The relationship between body mass index, treatment, and mortality in patients with established coronary artery disease: a report from approach. Eur Heart J 2009;30:2584-92.

20 Powell BD, Lennon RJ, Lerman A, et al. Association of body mass index with outcome after percutaneous coronary intervention. $\mathrm{Am} \mathrm{J}$ Cardiol 2003;91:472-6.

21 Wang L, Liu W, He X, et al. Association of overweight and obesity with patient mortality after acute myocardial infarction: a metaanalysis of prospective studies. Int J Obes 2016;40:220-8.

22 Shahim B, Redfors B, Chen S, et al. Bmi, infarct size, and clinical outcomes following primary PCl: patient-level analysis from 6 randomized trials. JACC Cardiovasc Interv 2020;13:965-72.

23 Flegal KM, Kit BK, Orpana H, et al. Association of all-cause mortality with overweight and obesity using standard body mass index categories: a systematic review and meta-analysis. JAMA 2013;309:71-82.

24 Kee CC, Sumarni MG, Lim KH, et al. Association of BMI with risk of CVD mortality and all-cause mortality. Public Health Nutr 2017;20:1226-34.

25 Berrington de Gonzalez A, Hartge P, Cerhan JR, et al. Body-mass index and mortality among 1.46 million white adults. $N$ Engl $J$ Med 2010;363:2211-9.

26 Hjellvik V, Selmer R, Gjessing HK, et al. Body mass index, smoking, and risk of death between 40 and 70 years of age in a Norwegian cohort of 32,727 women and 33,475 men. Eur J Epidemiol 2013;28:35-43.

27 Prospective Studies Collaboration, Whitlock G, Lewington S, et al. Body-mass index and cause-specific mortality in 900000 adults: collaborative analyses of 57 prospective studies. Lancet 2009;373:1083-96.

28 Flegal KM, Graubard BI, Williamson DF, et al. Cause-specific excess deaths associated with underweight, overweight, and obesity. JAMA 2007;298:2028-37.

29 Lavie CJ, Arena R, Alpert MA, et al. Management of cardiovascular diseases in patients with obesity. Nat Rev Cardiol 2018;15:45-56.

30 De Schutter A, Lavie CJ, Patel DA, et al. Relation of body fat categories by Gallagher classification and by continuous variables to mortality in patients with coronary heart disease. Am J Cardiol 2013;111:657-60.

31 Azimi A, Charlot MG, Torp-Pedersen C, et al. Moderate overweight is beneficial and severe obesity detrimental for patients with documented atherosclerotic heart disease. Heart 2013;99:655-60.

32 Lavie CJ, De Schutter A, Patel DA, et al. Body composition and survival in stable coronary heart disease: impact of lean mass index and body fat in the "obesity paradox". J Am Coll Cardiol 2012;60:1374-80.

33 McAuley PA, Smith NS, Emerson BT, et al. The obesity paradox and cardiorespiratory fitness. J Obes 2012;2012:1-6. 